\title{
Analysis and Suppression of Low Frequency Oscillations in Small Three-Bladed Vertical-Axis Micro-Hydro Turbine
}

\author{
Sy-Ruen Huang, Yen-Huai Ma, Wen-Shyong Kuo, Kazuichi Seki, and Jen-Han Yang
}

\begin{abstract}
This study analyzes Low Frequency Oscillations (LFO) phenomenon of small vertical axis type blades micro hydro turbine power generation system which installed in Shimen Open Channel in Taoyuan, Taiwan. Recent researches presented that the vertical axis wind turbine rotates unstably due to the vertical blades absorbing different fluid forces at different angles. This phenomenon affects the power system DC link voltage occurring low-frequency fluctuations, which significantly impacts the power supply output performance. In the study, small vertical axis blades of micro hydro turbine power generation system also have same problem which affect the voltage floating on the DC link, causing the system voltage unstable and affecting the quality of the output power. In order to suppress the impact of the above phenomenon, this study presents a feed-forward low-frequency feedback control method of suppressing floating voltage on the DC link to improve power quality and reduce the probability of failure. The paper includes a small vertical axis type blades micro hydro turbine power generation system instruction and its low frequency oscillations cause reasons; the establishment of low-frequency feedback feedforward control simulation models; analysis of the effect of suppressing voltage fluctuations. The study conclusions and recommendations can be provided to for further study.
\end{abstract}

Index Terms-Floating voltage, small vertical axis blades micro-hydro, low frequency oscillations.

\section{INTRODUCTION}

In recent years, renewable energy systems are rapidly developing due to fossil fuel depletion and environmental pollution problem of the crisis. Hydropower generation cost per $\mathrm{kWh}$ is obviously lower than the widely used thermal power, nuclear power, solar power, wind power [1], almost all developed countries choose hydropower priority to face threats of excessive greenhouse gas emissions.

Manuscript received September 30, 2013; revised December 25, 2013 This work was supported in part by the National Science Council of Taiwan for supporting the research under the grants of NSC101-2632-E-035-001-MY3 and NSC102-2221-E-035-078.

Sy-Ruen Huang is with the Department of Electrical Engineering Feng Chia University, Taichung, Taiwan, R.O.C. (e-mail: srhuang@fcu.edu.tw).

Yen-Huai $\mathrm{Ma}$ is with the $\mathrm{Ph}$. D. Program of Electrical and Communications Engineering, Feng Chia University, Taichung, Taiwan R.O.C. (e-mail: ahma5653@gamil.com).

Kazuichi Seki is with the Research Institute of Science and Technology, Tokai University, Tokai, Japan (e-mail: 1.grigsby@ieee.org).

Wen-Shyong Kuo is with the Department of Aerospace and Systems Engineering, Feng Chia University, Taichung, Taiwan, R.O.C.(e-mail: wskuo@fcu.edu.tw)

Jen-Han Yang is with the Master Program of Electrical Engineering, Feng Chia University, Taichung, Taiwan R.O.C. (e-mail: wertysh1@hotmail.com).
Micro-hydropower is currently a relatively new type of small hydro renewable energy which use irrigation channels water flow mechanical energy to generate electricity with benefits of environmental protection, economic efficiency and recycling energy. This system has advantages of simple architecture design, low cost, and environmental friendly. Fig. 1 shows small vertical axis type micro hydro turbine power generation system in operation. Many studies have presented that the vertical axis wind turbine, due to the vertical blades at different angles of attack caused by absorption of fluid forces, produce unstable power to make the DC link voltage into a low-frequency fluctuations, which have a significant impact on its power supply performance.

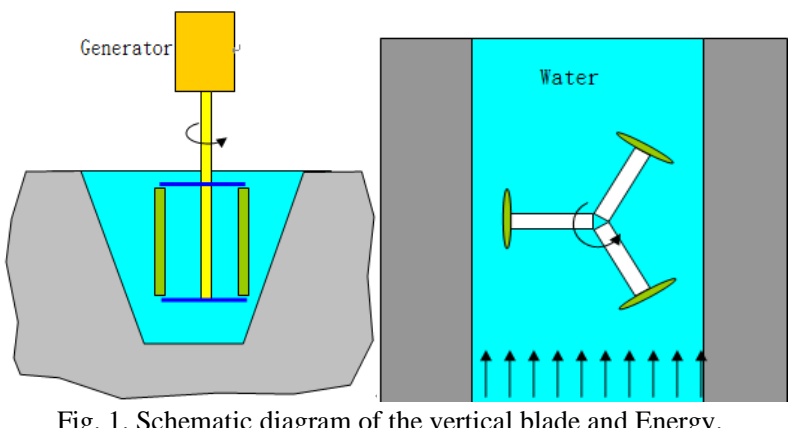

The capability to sufficiently stabilize voltage oscillations or floating on all bus is voltage stability which determines balancing the load and generators. In an unstable phenomenon may not just belong to the same type and may involve a variety of factors of instability more than one destabilizing factor. Different types of power system oscillation mode have been detected, researched, classified, and inhibited [2]-[4]. Small vertical axis micro hydro turbine power generation system connected to rotating blades, generators, inverters, and connected to the power grid. The system disturbance responses to any power system electromechanical oscillations will decay to stable or remain oscillating. If the oscillations keep increasing and then will affect power quality or destroy the system. In modern power system management and control, power quality oscillation monitoring is very important. Small vertical axis micro hydro turbine power generation systems produce low frequency voltage fluctuations because the vertical angle of vertical blades absorbing different fluid forces at different angles to generate different power. The DC voltage instability and the formation errors make high frequency switching inverter generate an instant high-current to damage components. Moreover, the unstable DC voltage will cause the inverter 
even generate floating alternating current to impact electrical power quality.

This study presents a feed-forward low-frequency feedback control method of suppressing floating voltage on the DC link to improve power quality and reduce the probability of failure. The main purpose of feed-forward feedback control is to stabilize a setting value. In this study, low frequency oscillations compensator separated from the AC voltage of a three-phase/three-wire generator, to the DC link. Therefore, feedforward feedback control requires rectification and low-frequency filter circuit to build a feedforward low-frequency feedback circuit to suppression floating voltage on DC link. The following sections describes the analysis of LFO (Low Frequency Oscillations) phenomenon observed from a small vertical axis type blades micro hydro turbine power generation system in Shimen Open Channel in Taoyuan, Taiwan. The second part describes the vertical axis wind turbine, due to the vertical blades at different angles of attack caused by absorption of fluid forces, have the power of the state is not stable and mapping in the power system frequency DC link voltage floating phenomenon. The third part describes the feedforward control method suppresses low-frequency feedback voltage on the DC link floating and modeling. Section IV is simulation results and related analysis; Section V is conclusions.

\section{Vertical Axis Turbine Blade TyPe Micro-Hydro POWER GENERATION AND FLUID MECHANICS}

Experiments show that a small three-bladed vertical axis wind turbine (SB-VAWT) rotates unstably to affect output power by low-frequency oscillations [4]-[9]. Using Reynolds Averaged Navier Stokes equations (RANS) for three-dimensional instability flow field simulation results show that when the blades rotate once at different angles of attack of the blade and the blade uneven fluid dynamics and interactions, the force acting on the shaft in the cyclical changes in the role of this imbalance force is constantly rotating blades push factors, as shown in Fig. 2.

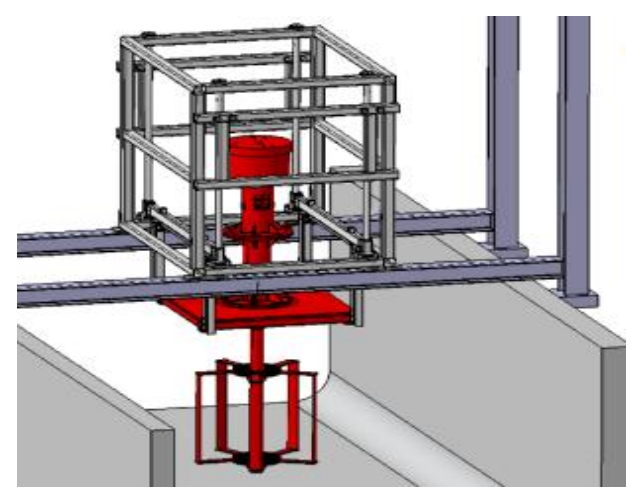

Fig. 2. Design concept of a small vertical-axis micro-hydro turbine.

This study uses streamtube theory first proposed by Strickland in 1975[10] to analyze hydrodynamics. This theory using Glauter's boundary element method (BEM theory) and the average time to get the flow of power flow momentum equation, however, the blade Reynolds number and dynamic stall effects do not be considered. About horizontal and vertical forces on blades while blades start and stably rotate, we consider the blade forces equal air moving power:

$$
\begin{gathered}
F_{x}=\dot{m}\left(V_{\infty}-V_{\text {wake,hori }}\right) \Rightarrow V_{\infty}-V_{\text {wake,hori }}=\frac{F_{x}}{\dot{m}} \\
F_{y}=\dot{m}\left(0-V_{\text {wake,vert }}\right) \Rightarrow-V_{\text {wake,hori }}=\frac{F_{y}}{\dot{m}}
\end{gathered}
$$

The calculated value is used to calculate the strength of the front end and the rear end fluid velocity fluid velocity.

Fig. 3 and Fig. 4 present attack angle formed, torque and direction of the water forces on micro-turbine blades one rotation. This study uses asymmetric S1223for micro hydraulic blades. Fig. 3 (a) shows that when the blade is 60 degrees azimuth and angle of attack is 10 degrees the blades generate lift without much resistance because the blade of S1223 generated negative lift coefficient and a negative torque as shown in Fig. 5. When the blades rotate through the negative torque angle area to achieve an azimuth angle of 90 degrees, angle of attack at this point is zero degree. Therefore, the lift force of blades is negligible. Fig. 4 (a) presents the appropriate torque which in a process of upcoming transitions.

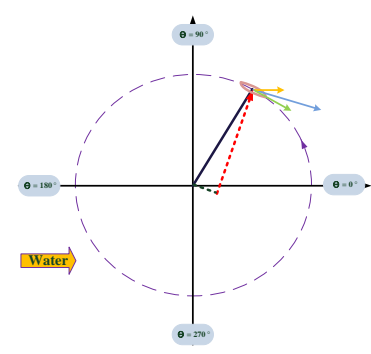

(a)

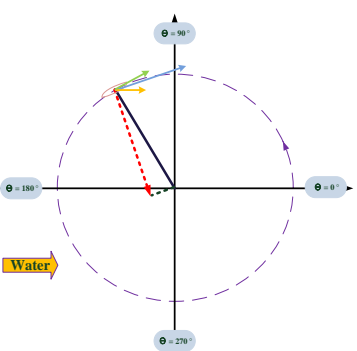

(c)

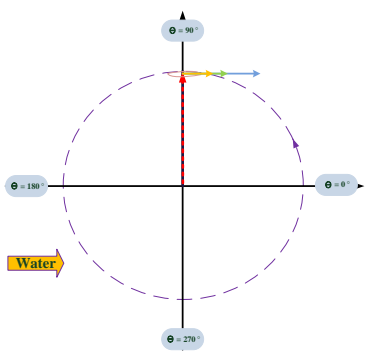

(b)

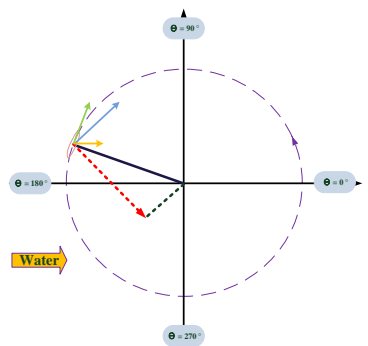

(d)

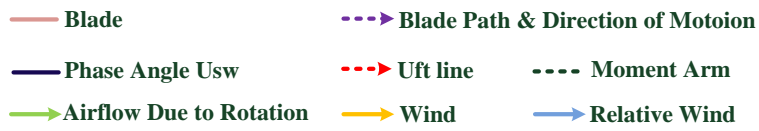

Fig. 3. Micro-hydro blade tangent angle torque vector of $60^{\circ}, 90^{\circ}, 120^{\circ}, 160^{\circ}$
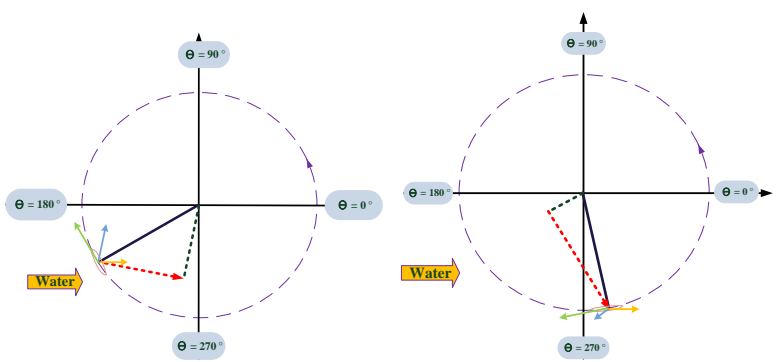

Fig. 4. Micro-hydro blade tangent angle torque vector of $210^{\circ}$ and $280^{\circ}$

Turbine blades rotate shaft 90 slightly offset from the lift line (Fig. 3(b) the brown dotted arrows), provide the lift torque. The resistance of blade still exists, but a larger torque (the length of the brown dotted arrow) than the resistance make blades generate a positive torque to overcome the 
resistance of a drag force formed by the negative torque.

When the blade is rotated to about 120 degrees azimuth almost up to the maximum value of torque, as shown in Fig. 3 (c). This position corresponds to about 20 degrees angle of attack is the best angle of attack. This perspective has also led to a long lift arm length. Blades over the azimuth of 120 degrees, the torque are then decreased until the azimuth of 180 degrees. In this position, the angle of attack (about 40 degrees) is too large to resist the blades.

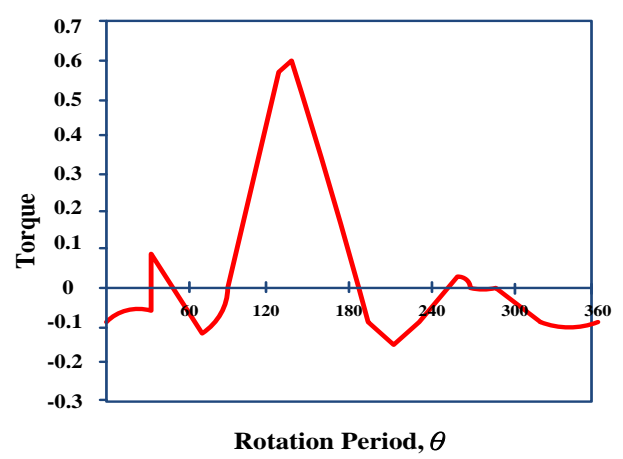

Fig. 5. Micro-hydro blade torque vector.

From azimuth 180 to 240 degrees, the torque begins to decrease as shown in Fig. 4 (a). In this area, the angle of attack is the best value at about 20 degrees. But water leaves the same as the moving direction, thus acting on the blade hydraulic power is low, resulting in low Reynolds number.

In the rest of the azimuth 280 degrees from 360 degrees, the water flow force to the blade is influenced by water flow force to upstream blade and other interactions force will force alone is not complete or under normal circumstances, as the water leaves the force of suffered. Proposed in the literature gives us a more accurate simulation of the force generated by the predicted case [11]-[13], as shown in Fig. 4 (b). Literatures' results indicate that the most negative torque occurs at about 330 degrees azimuth.

Micro hydro turbine can generate torque coefficient is based on the analysis from said fluid. Fig. 5 presents micro turbine blade torque generated by rotation torque.

\section{Micro Hydro TURBINE POWER SySTEM AND LOW FREQUENCY OSCILLATIONS}

This study installed a small three vertical axis turbine blade micro turbine in Shimen Open Canal in Taoyuan, northern Taiwan. The blades of generator are about 3 meters depth under the water. The location is longitude: $121^{\circ} 10$ '45 ", latitude: $24^{\circ} 57^{\prime} 20^{\prime \prime}$; the average temperature, $34^{\circ} \mathrm{C}$ and average water flow rates of $3.0 \mathrm{~m} / \mathrm{s}$. Micro-turbine generator set is mounted in a laboratory above water. There are instruments recording the measured data in the laboratory. A measurement of turbine speed tachometer installed at the micro-turbine generator record rotation speed to measure water flow speed and power.

The generator generates rated output power $9 \mathrm{~kW}$ at $3 \mathrm{~m} / \mathrm{sec}$ and the blade angle is 7 degrees. A permanent magnet generator generates $\mathrm{AC}$ power and then converts to $\mathrm{DC}$ power through the three-phase bridge rectifier. Generator output power dissipated in the load with constant voltage turbine braking resistor. Fig. 6 shows the block diagram of the circuit.

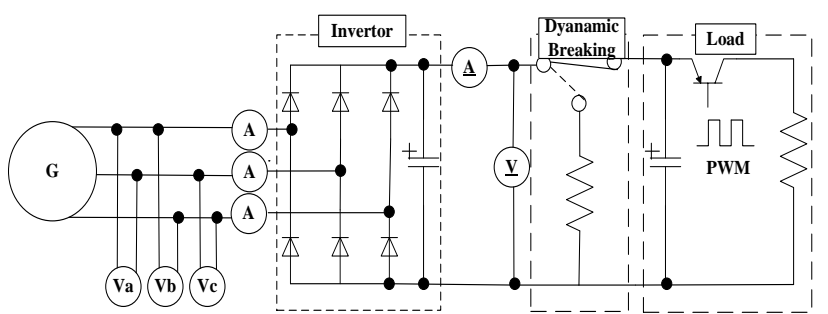

Fig. 6. Integrated solid-state controller synchronous generator and load system configuration.

Micro-turbine power generation system uses the uncontrollable three-phase rectifier as shown in Fig. 6. Fig. 6 also shows the permanent magnet synchronous generator, three-phase diode bridge rectifier, brake resistors and constant voltage load of the system configuration. When the turbine in operation, the permanent magnet synchronous generator generates output power and the three-phase diode bridge rectifier rectifies the AC into DC output to the load. DC bus capacitors are used to suppress the voltage ripple depends on its capacitance value. If filter capacitor value is too small, it just can suppress high frequency but not low frequency voltage variety. If capacitor is too high, it would be high price and larger volume, moreover, respond slowly with high frequency.

Fig. 5 presents single micro turbine blade rotation torque generated by the torque. This study experiment a three-blade vertical direct-drive generator, which's three-blade angles are 120 degrees because the lower the power suffered everywhere in different imbalance between the pulling torque at the same time, thus forming the rotating shaft rotation state. This is an inevitable characteristic vertical generator, the generator being in need of such vertical imbalance vector, side rotation state can be formed. Fig. 7 presents a simulation diagram of three-bladed vertical direct drive hydroelectric. This generator has the vertical imbalance in rotation characteristics, brings its power for rotating and thus generates energy. However, this indispensable rotational torque imbalance in the power system, but also mapped DC chain to form a low float voltage. According to Fig. 6 micro- hydroelectric system architecture, we can see the water driven turbine energy through the rotation to produce energy. Due to the direct drive generator, the blade torque directly reflected the rotational speed of the generator. Not even rotational speed of the generator will generate an imbalance power relatively, and the generator output low frequency floating. Fig. 8 is a micro hydroelectric measuring voltage waveform diagram of the output. This phenomenon of low frequency floating voltage can be seen in Fig. 8, due to torque changing of three blades.

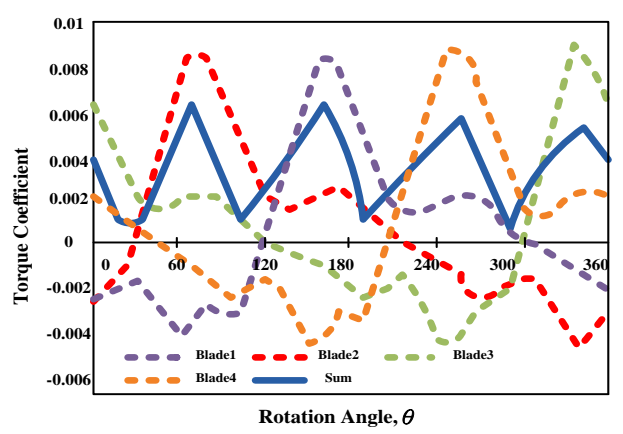

Fig. 7. Three-bladed vertical direct drive hydroelectric three-blade composite torque mimic diagram. 


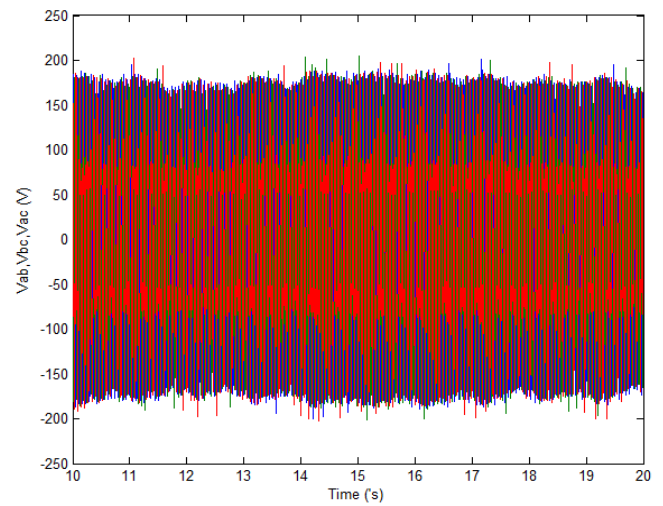

Fig. 8. End to end micro-hydroelectric output voltage waveform.

The three-phase generator generates AC outputs to diode bridge rectifier convert into DC at the output terminal. Vice-voltage rectifier into half weeks after the positive half cycle, the voltage floating phenomenon is more obvious. Therefore, the DC link voltage can be significant due to the occurrence of vertical hydroelectric torque imbalance resulting low-frequency voltage fluctuations. Fig. 9 is a micro hydro machine measuring DC voltage waveform; the variable DC voltage frequency phenomena significantly compared to the AC side. Fig. 8 and Fig. 9 are the same period of time measured voltage AC and DC side. Fig. 9 is a high-frequency noise from the rear of the high frequency output to the load switching. Fig. 10 shows that low-frequency in three vertical micro hydroelectric power systems in the process. Affected by the blade by hydro generator output and the DC voltage connected to the floating state enables low-frequency DC link power system cannot maintain a stable DC, this will cause the rear float voltage high frequency switching inverter is misjudgment or unstable state, even make generators off the power grid.

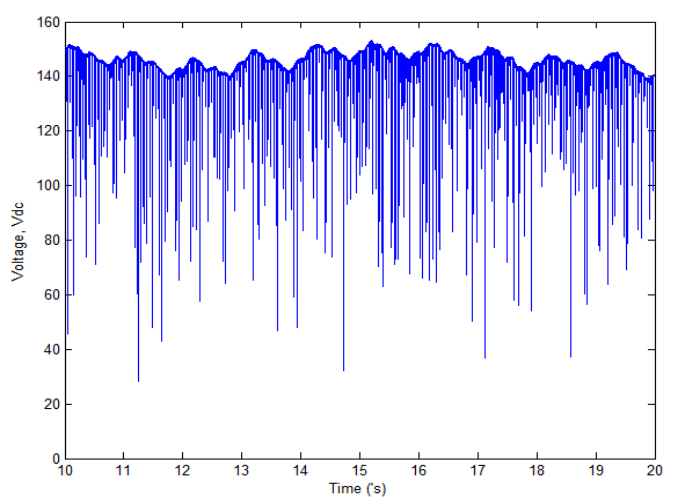

Fig. 9. Micro-hydroelectric DC side voltage waveform.

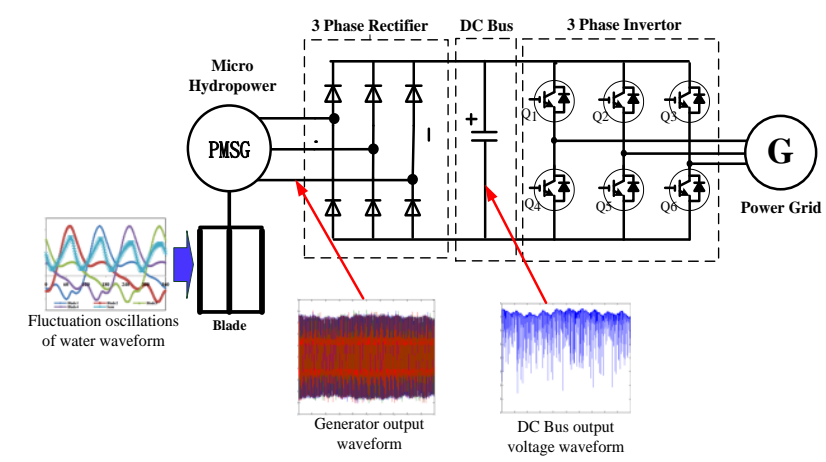

Fig. 10. Low-frequency phenomena presented in three Vertical micro hydroelectric power system.

\section{Micro Hydro Turbine-BASEd POWER SYSTEM ANALYSIS AND LOW FREQUENCY VIBRATION SUPPRESSION METHOD}

Because the flow imbalance caused by voltage unbalance relations, measured low-frequency voltage data to analyze the frequency components using Matlab Fourier analysis as shown in Fig. 11. The $30 \mathrm{~Hz}$ frequency component is quite high, especially in the low-frequency component amount $1.5 \mathrm{~Hz}$ particularly high, whereby the frequency of the voltage waveform chart can prove low-frequency phenomenon. In order to suppress the occurrence of low-frequency, low-frequency proposed feedforward control method for suppressing the feedback voltage on the DC link floating, containing the low-frequency filtering of the voltage, via the compensation method to the dc link, to provide a stable voltage and listing electricity, the method as shown in Fig. 12.

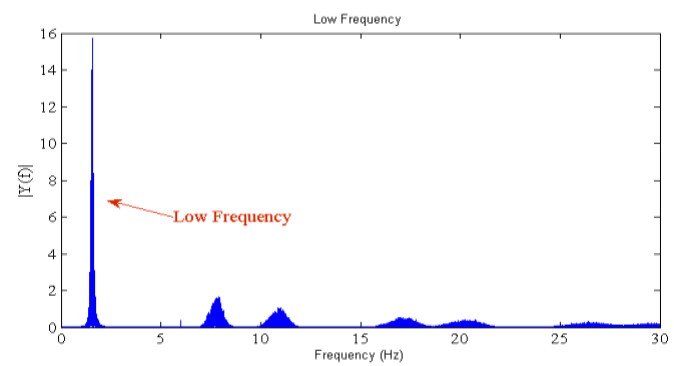

Fig. 11. Frequency analysis chart.

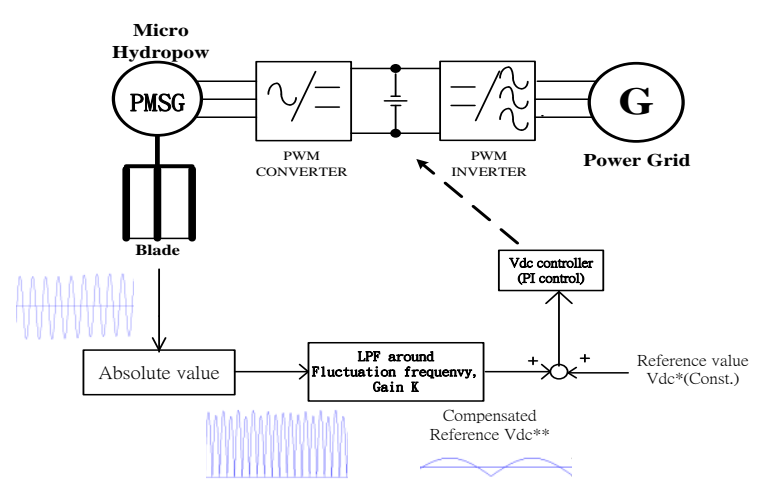

Fig. 12. Feedforward control method for low-frequency feedback schematic.

Feedforward control method for low-frequency feedback output feedback voltage compensation generator output to the DC chain. However, the generator output is a three-phase three-wire alternating current, and the output voltage and low frequency oscillation AC output we need to use the generator end of the first measure to low frequency waveform, frequency band-pass filter will filter off, and the remaining low-frequency component containing the absolute value of the fundamental wave through, and then into the fundamental wave band-pass filter will filter out the rest of the low-frequency waveforms multiplied by a factor, the value is compared and a DC voltage, and through PI control to compensate for floating voltage on the DC link.

\section{Simulation Results}

In this paper, Matlab / Simulink to simulate low-frequency feedback feedforward control method, the model structure shown in Fig. 13. In Fig. 14, the $\mathrm{R}$ is the actual measurement of the generator to the single-phase AC voltage, to the low-pass filter, and compared to the reference voltage $\mathrm{V}$, then 
the signal is sent back to the DC side compensation, the compensation results shown in Fig. 15. Fig.15 from top to bottom, respectively, single-phase voltage of the generator, the filtered DC voltage and DC voltage, the generator can be seen from the figure that some promise single-phase voltage frequency phenomenon, the DC voltage waveform frequency oscillation particularly evident after feedforward compensation feedback control frequency, can be more stable DC voltage, in this way to suppress the occurrence of low frequency oscillation, to the power system more stable output.

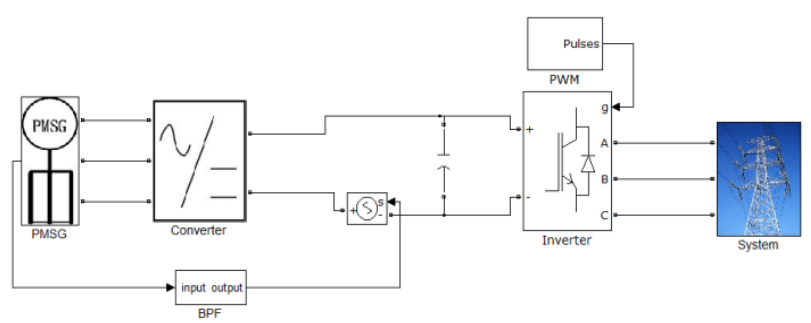

Fig. 13. Micro-hydro-motor feedback control model diagram.

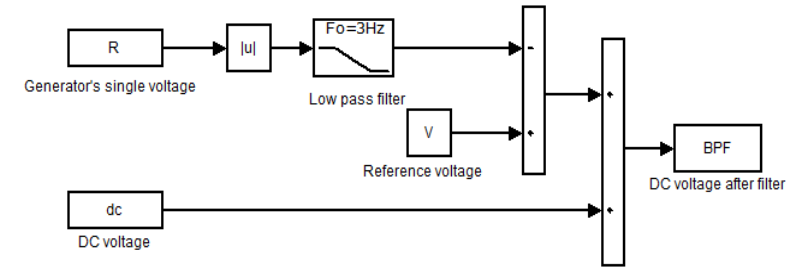

Fig. 14. Low-frequency feedback control feedforward model diagram.
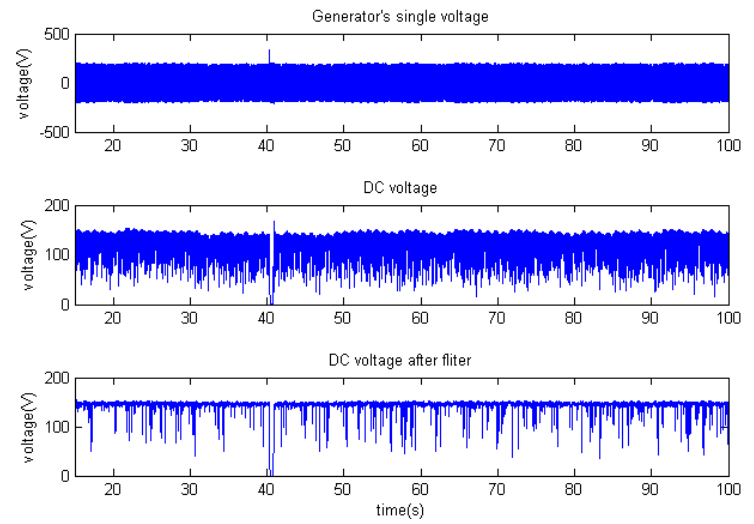

Fig. 15. Voltage waveform of Micro-hydro Turbine.

Fig. 16 is a DC voltage of the frequency analysis before and after filtering, and Fig before filtering the DC voltage in the frequency below $30 \mathrm{~Hz}$ is still quite high, especially in the $1.5 \mathrm{~Hz}$ place, but after the first feedback control and feed-forward frequency filtering, it is obvious reduce the low frequency component, that the control mode can be effectively suppressed low.
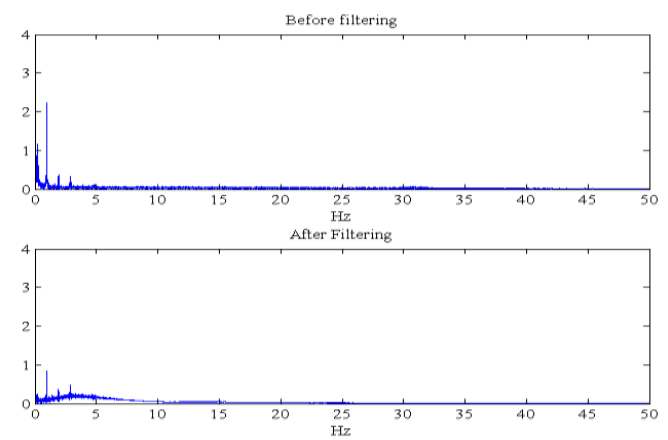

Fig. 16. DC voltage before and after filtering frequency analysis chart.

\section{CONCLUSION}

This study analyzes low-frequency oscillations of a small vertical axis turbine blade type micro-hydro power system in Shimen Open Channel in Taoyuan, Taiwan, and proposes a feedforward feedback control method to suppresses floating low-frequency voltage on the DC link to improve electricity quality and reduce the probability of failure. This study establishes a low-frequency feedback feedforward control method model and simulates the effect of suppressing voltage fluctuations using Matlab/Simulink. Fourier analysis of the frequency components of the measured data results that the generator output waveform contains components of frequency below $30 \mathrm{~Hz}$, moreover, the low-frequency, $1.5 \mathrm{~Hz}$, is particularly high. Therefore, frequency component amount of $1.5 \mathrm{~Hz}$ is necessary to be suppressed in this case. The frequency of the voltage waveform diagram also presents the voltage wave contains multiple low-frequency phenomenon.

Small vertical axis micro hydro turbine power generation system has a low frequency oscillation phenomenon, especially the DC voltage frequency oscillation particularly high. The low-frequency feedback feedforward control can compensate stable DC voltage to suppress low-frequency and the power system can output power stably. The simulation results shows that DC link voltage is stable and inverter also produce stable AC after compensation of low-frequency feedback feedforward control method.

\section{ACKNOWLEDGEMENTS}

The authors thank the National Science Council of Taiwan for supporting the research under the grants of NSC101-2632-E-035-001-MY3 NSC102-2221-E-035-078.

\section{REFERENCES}

[1] California Levelized Energy Costs for Different Generation Technologies in US Dollars Per Megawatt Hour, 2007.

[2] P. Kundur et al., "Definition and classification of power system stability," IEEE Trans. Power Syst., vol. 19, no. 2, pp. 1387-1401, May 2004.

[3] R. Farmer, "Power systems dynamics and stability," in The Electric Power Engineering Handbook, L. Grigsby, Ed. Boca Raton, FL: CRC, 2001.

[4] X. N. Ji et al., "Design and analysis of small-scale vertical axis wind turbine," in Proc. IET Conference on Renewable Power Generation, 2011, pp. 1-10.

[5] S. Read and D. J. Sharpe, "An extended multiple streamtube theory for vertical axis wind turbines," in Proc. 2nd BWEA Workshop, Cranfield, U.K., Apr. 1980, pp. 65-72.

[6] I. Paraschivoiu, "Double-multiple streamtube model for darrieus wind turbines," in Proc. Second DOE/NASA Wind Turbines Dynamics Workshop, Cleveland, OH, February 1981, pp. 19-25.

[7] A. C. Mandal, "Aerodynamics and design analysis of vertical axis darrieus wind turbines," Ph.D. dissertation, Brussel:Vrije Universiteit, Belgium, 1986.

[8] D. J. Sharpe, A Theoretical and Experimental Study of the Darrieus Vertical Axis Wind Turbine, Polytechnic School of Mechanical, Aeronautical and Production Engineering, 1977.

[9] B. Pai and B. Chaudhuri, Robust Control in Power Systems, New York: Springer, 2005.

[10] J. H. Strickland, "A performance prediction model for the Darrieus turbine," in Proc. International Symposium on Wind Energy Systems, Cambridge, UK, pp.C3:39-54, Sep.1976.

[11] O. de Vries, Fluid Dynamic Aspects of Wind Energy Conversion, .AGARD, 1979.

[12] P. Psarudakis and A. Satta, "Ir method for the analysis of the unsteady flow of vertical axis wind turbines," presented at the EWEC Conf., Rome 1986. 
[13] R. Roucous, A. Zervos, and P. Devinant, "A vortex model of the VAWT including instantaneous blade rotation effects," presented at EWEC Conference, Rome 1986.

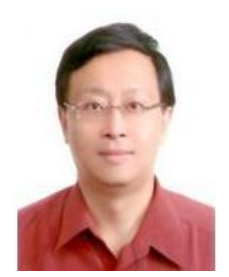

Sy-Ruen Huang received the B.S. degree from Feng Chia University, in 1988, and the M.S. and Ph.D. degrees from National Tsing Hua University, Taiwan, in 1989 and 1993, respectively. In 1993, he joined the faculty of Feng Chia University, Taiwan, where he is currently a professor. His research interests include power system protection and power quality.

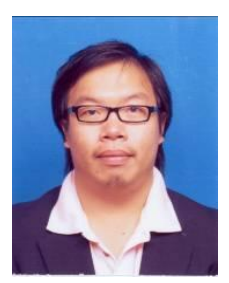

Yen-Huai Ma received the B.Sc. degree and M.Sc degree in Department of Electrical Engineering from Feng Chia University, Taichung, Taiwan, R.O.C in 2009 and 2012. He was with the Ph.D. program of Electrical and communications engineering, Feng Chia University, Taichung, Taiwan R.O.C. in 2012. His current studies include renewable energy, green energy, power system, power electronic, artificial intelligence, power system protection and power quality.

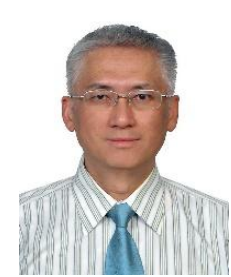

Wen-Shyong Kuo received the B.Sc. degree in mechanical engineering from National Chiao-Tung Univ., Taiwan in 1981, the M. Sc. degree from National Tsing-Hua Univ., Taiwan in 1984, and the Ph.D. from Univ. of Delaware, U.S.A. in 1992. In 2005, he was a visiting scholar to the Dept of Mechanical Engineering and the Center for Composite Materials, Univ. of Delaware. He joined the Feng Chia University as an associate professor in 1992 and became a professor since 1999. He has been with the Department of Aerospace Engineering in FCU. His current research interests include composites, nano-carbon, and composite structures. He is the author of five books in composite materials, and he has published more than 60 papers in international journals. Since 2000, he has been the member of the Board of Directors, SAMPE, Taiwan Chapter.

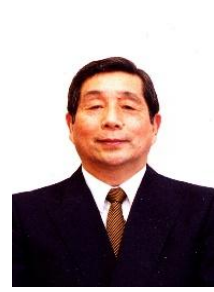

Kazuichi Seki was an assistant professor of the Institute of Space and Aeronautical Science of the University of Tokyo, Tokyo, Japan in 1963-1975. In 1976-1990, he joined the Research Institute of Science and Technology of Tokai University, Kanagawa, Japan as an associate professor and become a professor since 1991. Also, he is an executive officer of Energy Research Center, Ming Dao University, Taiwan since 2006. His current Studies on low-subsonic aerodynamics, transonic aerodynamics, and supersonic aerodynamics and hypersonic aerodynamics. Studies on environmental engineering, windmill engineering, rockets, and aerodynamics of flying objects. Studies on applied aerodynamics of vehicles, sphere-shaped objects, long-span bridges, and structural objects. Studies on atmospheric dispersion, and the ventilation of long tunnels. Study on energy conversion engineering. Studies on wind characteristics and wind power systems of varied size. Study on human-powered aircrafts.

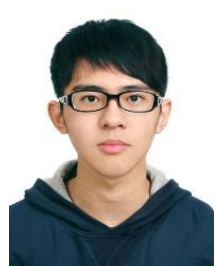

Jen-Han Yang has received the B.Sc. degree in Department of Electrical Engineering from Feng Chia University, Taichung, Taiwan, R.O.C in 2012. He was with the master program of Electrical and Communications Engineering, Feng Chia University, Taichung, Taiwan R.O.C. in 2012. His current studies include renewable energy, green energy, power electronic and power quality. 